\title{
Application of Traditional Chinese Medicine Knowledge Contained in Dragon Boat Festival Customs in Teaching Chinese as a Foreign Language Culture
}

\author{
Wang Wenyan ${ }^{1, a}$, Wen Yongyi ${ }^{2}$, ${ }^{*}$
}

1College of Humanities and Management, Shaanxi University of Chinese Medicine, Xianyang, Shaanxi, China 2College of Foreign Languages, Shaanxi University of Chinese Medicine, Xianyang, Shaanxi, China a1448143186@qq.com

b*1121602719@qq.com

\begin{abstract}
The Dragon Boat Festival,as a traditional Chinese festival, has handed down many folk customs, such as eating zongzi, rowing dragon boats, hanging Acorus calamus, inserting wormwood, etc.These Dragon Boat Festival customs are closely related to the traditional Chinese medicine culture, which reflects that the ancient Chinese ancestors had the awareness of safety and epidemic prevention. The ancients have gradually understood the efficacy of traditional Chinese medicine wormwood, Acorus calamus and realgar in their daily life. This article mainly takes the customs of the Dragon Boat Festival as the starting point, and analyzes the knowledge of traditional Chinese medicine contained in traditional Chinese festivals and customs and its importance in teaching Chinese as a foreign language. Explore the application methods and realization ways of traditional Chinese medicine culture in teaching Chinese as a foreign language, so as to formulate a scientific teaching design of traditional Chinese medicine culture course. It plays a role in strengthening the communication power and influence of traditional Chinese medicine culture at the cultural level in the process of external communication.
\end{abstract}

Keywords : Chinese as a foreign language, Dragon Boat Festival Customs, Traditional Chinese Medicine Culture, Cultural teaching

\section{端午节习俗中蕴含的中医知识在对外汉语 文化教学中的应用探究}

\section{王文燕 ${ }^{1, a}$ ，闻勇毅 ${ }^{2, b *}$}

\author{
1 陕西中医药大学人文管理学院, 咸阳, 陕西, 中国 \\ 2 陕西中医药大学外语学院, 咸阳, 陕西, 中国 \\ a1448143186@qq.com \\ b*1121602719@qq.com
}

\section{摘要}

中国传统节日端午节流传下了许多民间习俗，如吃粽子、划龙舟、挂菖蒲、插艾草等，这些端午习俗与传统的 中医文化有密切的联系，反映了中国古代的先民已经拥有了安全防疫意识，在日常生活中已经逐渐了解了这些 药草具有的功效。本文主要以端午节的习俗为切入点, 以小见大, 分析中国传统节日习俗中蕴含的中医知识及 其在对外汉语文化教学中的重要性, 探索中医药文化在对外汉语教学中的应用方法和实现途径, 从而制定科学 的中医药文化课程的教学设计, 为中医药传统文化在对外传播过程中强化其文化层面上的传播力和影响力发挥 
一些作用。

关键词：对外汉语；端午节习俗；中医药文化；文化教学

\section{1. 前言}

中医药文化博大精深，在传播的过程中，如何与 对外汉语教学联系起来, 促进中医药文化的发展和世 界文明的进步, 是一个函待解决的重要课题。中医药 文化因其涉猎范围广泛, 很难从整体上把握, 所以我 们需要选择能将中医药和对外汉语文化教学有机结 合起来的媒介, 而它的一个切入点一一中国传统节日 端午节或许可以成为对外汉语文化教学的新视角。本 文便拟从中国传统节日端午节中蕴含的中医药知识 与对外汉语文化教学相结合的角度出发, 选取其中具 有中医文化内容的节日习俗进行中医文化课教学设 计分析, 以期能够创新中医文化在对外汉语教学中的 内容, 促进中医文化的传播和发展。

\section{2. 端午节习俗中蕴含的中医药知识}

五月初五端午节, 正值春夏之交, 蚊虫滋生, 容 易爆发瘟疫疾病。先秦时期的古人认为五月是个 “毒 月”, 为保护生命, 驱邪预疾, 已经具有了防疫保健 的意识, 并采取了一系列的医药措施, 这些在端午节 的民俗活动中得到了验证。

\section{1 医药防疫}

端午节的标志性习俗是挂菖蒲、插艾草，有民浐 云: “五月五日午, 天师骑艾虎, 手执菖蒲剑, 蛇虫 归地府。” ${ }^{[1]}$ 菖蒲和艾草都是中药, 艾的茎叶含有挥 发性芳香油, 产生的特殊芳香, 可以驱蚊, 净化空气。 菖蒲叶片形似宝剑, 又称 “蒲剑”, 能够开窍宁神, 祛痰化湿, 人们将它挂于门口, 起到禳毒辟邪的作用。 端午也是一些根茎入药的植物采集的好时节, 这时候 许多草药茎叶已经成熟, 所以在浙江、湖北等地有端 午上山 “采百草” 的习俗。古代的端午节又称为 “浴 兰节”, 此兰为菊科的佩兰, 有香气, 可煎水沐浴, 后来发展成用煎蒲、艾等香草洗澡, 以祛湿止痒驱虫。 佩香囊又是人们防疫的一个举措, 古人用鲜艳的布料 缝制香囊, 内里装有白芷、丁香、肉桂、薄荷等具有 芳香气味的中药, 人们吸入这些中药的特殊气味, 从 而达到调节阴阳、预防疾病的目的，体现了中医 “治 未病” 的先进思想以及古人重视环境卫生的超前意 识。

\section{2 饮食养生}

中医饮食养生的智慧在端午节中的体现就是流 传至今的习俗一一吃粽子。粽子是由粽叶包裹糯米蒝 制而成, 传统的粽叶是菰叶, 一种水生可食叶片, 现 代多用竹叶或荷叶包裹, 这些叶片能够清热、解毒、 消食、健胃, 有助于降低粽子的粘㖑之性, 加快机体 对粽子营养成分的吸收。粽子的主料糯米性甘平, 能 温暖脾胃, 补益中气。端午节有的地区还有饮雄黄酒 和菖蒲酒的习俗, 雄黄是一种矿物质, 有杀菌驱虫解 五毒的功效。一般饮用的雄黄酒, 只是在白酒或自酿 的黄酒里加入微量雄黄而成, 因为雄黄酒有毒, 饮用 有一定危险性。主要目的是辟邪防疫。菖蒲酒具有提 神开空、化痰和胃、强身健体的功效, 《本草纲目》 记载用石菖蒲 “上药煎汁, 或酿或浸”, 菖蒲酒主治 “三十六风, 一十二痹, 通血脉, 治骨瘘, 久服耳目 聪明”。可见菖蒲酒在养生保健方面的功效。

\section{3 运动健身}

端午节的一项延续至今的重要民间娱乐活动就 是赛龙舟, 又称为 “龙舟竞渡”。据南北朝时期梁朝 人宗懔所撰的《荆楚岁时记》记载: “五月五日竞渡, 俗为屈原投汨罗日, 人伤其死, 故并命舟楫以拯之, 至今竞渡是其遗俗。” 作为一种群体性的体力运动赛 事, 赛龙舟的活动让运动的人全身得到拉伸舒展, 有 利于畅通经络, 全身的气血得到运行, 从而达到既能 强身健体, 又能愉悦身心的效果。这项群众性的运动, 从健康养生的角度来说, 不仅是对参赛者体力的锻炼, 对看赛者来说, 也有调节情绪、放松心境的抚慰作用。 古代端午节的强身健体类的活动还有荡秋千、射箭、 打马球等, 在广东地区还有放风筝的活动, 这些体育 卫生活动的开展, 展示了古人对生命的敬畏, 也体现 了古人清洁祛毒, 健身䙛灾的医学防疫思想。

\section{3. 端午节习俗中蕴含的中医知识在对外汉语 文化教学中的重要性}

\section{1 创新对外汉语教学的内容体系}

学好汉语是推广中医文化的前提, 对中医文化有 更精深的理解和研究需要用熟练的汉语作为支撑。而 中医药文化作为中国优秀传统文化的一部分, 自身具 有完整严密的文化内容、以及独特的文化理念, 能够 
在对外教学中充分展示中国优秀传统文化的精神内 容, 更有利于留学生从整体、宏观的角度理解中国文 化, 从而更好地学习汉语、了解中国文化, 利于中医 药教育的国际化发展。从传统节日出发, 把中医与传 统节日文化更好地结合起来, 利用节日传播中医文化。

\section{2 缓解对外汉语教学中的文化冲突}

近年来, 由于语言障碍导致的文化冲突现象时有 发生, 这也是影响中医文化推广与渗透效果的重要因 素, 因此在推广与渗透中医文化时, 必须要在对外汉 语教学基础上来进行。对外汉语教学是实施中医文化 推广的重要语言支撑, 而开展语言教学时, 中医文化 所具有的思维与知识结构等又能借助文化渗透和体 验的方式予以阐述, 从而有效减少了因文化碰撞而出 现的文化冲突等现象的发生, 有效提升了学生对中医 文化的认同感。端午节等传统节日在对外留学生群体 中具有一定的认知和熟悉度, 通过对传统节日趣味性 的引导和教学, 有利于加强学生对中国文化的学习。

\section{4. 教学设计的理念}

教学设计的目的是要达到教学效果最优化, 加涅 曾在《教学设计原理》(1988 年) 中将其界定为: “教 学设计是一个系统化规划教学系统的过程。” 也就是 说教学设计是在实施教学之前, 根据课程性质、教学 目标以及教学对象的特点, 运用科学的方法合理安排 教学内容, 教师选择合适的教学方法和策略, 在实施 的过程中对教学进行评估, 以达到教学目标 ${ }^{[2]}$ 。教学 设计将教学的各个要素组合在一起, 明确了 “为什么 学” “学什么” “怎么学” “学习效果” 等一系列连贯 的教学过程, 能够在实施教学之前最大限度地安排教 学流程, 让学生在单位时间内了解到更多的知识, 提 高学生的学习效率和学习质量。本文从中医文化课的 特点出发, 分别对课程设置、教学对象、教学目标和 教学方法等进行了简单分析, 为具体且系统的教学方 案提供参考。

\section{5. 教学设计分析}

\section{1 课程介绍}

中医文化课是以 “端午习俗中蕴含的中医知识” 为主题, 面向中高级阶段留学生开设的中医系列文化 选修课。教学内容主要包括端午习俗及其蕴含的中医 文化理论, 通过知识讲解以及技能操练, 让学生了解 传统节日中的医药原理和文化内涵。本文主要是以端 午节为切入点进行分析, 因为端午节习俗中蕴含了丰 富的医学防疫养生内容, 还体现了中国传统文化源远 流长的历史演变, 以此来进行教学设计不仅让留学生 了解到中国优秀的传统文化, 还能让学生感受到中医 文化博大精深、影响深厚的重要作用。

课程名称：端午习俗中的中医文化
课程对象: 中高级阶段留学生

课程类型：文化类选修课，包括理论和技能课程

授课时间: 2 周，每周 1 课时，共 2 课时

教学内容: 选取具有典型代表性的端午节日习俗, 介绍其蕴含的相关中医理论、医药知识以及实践操练 等。

\section{2 课程教学设计分析}

\subsection{1 教学对象}

教学对象影响着教师对教学活动的安排, 是教学 活动中的重要一环。本课程的教学对象选择为中高级 水平的汉语医学留学生, 因为课程中不仅只是表面的 介绍传统节日习俗, 更重要的是让学生在了解这些习 俗的过程中体会到其中蕴含的中医文化知识, 所以学 习者需要具备一定的汉语水平和中医文化知识储备。 课堂的文化知识讲解主要是以汉语为主, 对学习者的 汉语词汇量以及语法理解能力提出了更高的要求, 因 此, 汉语初级水平的留学生以及短期汉语学习者不具 备开展本科程的要求。为了能达到较好的学习效果, 所以本课程选择的教学对象为中高级水平的汉语医 学留学生。

\section{2 .2 教学目标}

中医文化课的教学目标是学习者在传统的习俗 活动中了解中医传统文化及其长期对人们生活产生 的影响。学生通过了解端午节习俗, 学习到古人关于 端午节日中防疫禳毒、中医养生以及运动健身的医学 文化知识, 从而更好地理解和掌握中国国情和文化背 景, 进一步促进汉语的学习, 减少学习者因为跨文化 交际产生的沟通问题。实践中加强手工操练活动, 鼓 励学生在动手实践中体会中医文化的趣味性, 营造良 好的学习环境, 激发学生的学习兴趣。在文化层面上, 更好地推广优秀的中国传统文化, 扩大学习者对中医 文化的认识, 以期能激发对中医文化的兴趣, 推动中 医传统文化的传播。

\section{2 .3 教学内容的选择}

\subsubsection{1 课程资源}

课程资源包括校内资源和校外资源。校内资源主 要有两方面, 一是教师和学生, 教师和学生是教学的 重要人力因素, 教师是实施中医文化课的主体，应该 选用具有中医文化知识背景的相关专业毕业生或是 经过中医专业学习的对外汉语文化课老师; 学生是中 医文化课的核心因素, 学生的汉语基础、学习动机、 学习态度等都影响课程资源的运用效果。二是教学的 场所、用具、资料等物质因素, 其中硬件设施包括中 医文化课实施的教学场所、实施技能操练的用具以及 相应的多媒体设备，文字性的资源包括中医文化教材、 
网络影像资源、多媒体课件、板书等。

校外资源包括有关的中医文化场所，包括针炎推 拿馆、中医药房、以及学生日常行为中能接触收到的 中医技艺。实践体验课, 在有条件下组织同学们体验 艾炎、制作香囊、划龙舟等, 感受节日中的中医文化 氛围 ${ }^{[3]}$ 。

\subsubsection{2 课程内容}

作为中医文化课, 在课程的选择上, 既要注重传 统民俗文化的传播, 又要通过浅显有趣的讲解让同学 感受到中医的深厚底蕴。

本课第一节简单介绍端午节的历史起源, 引出流 传至今具有代表性的习俗; 第二节, 介绍这些习俗中 蕴含的中医文化类型, 让学习者感受到中医文化悠久 的历史底蕴, 同时感受到古人的生活方式以及民俗民 风, 感受中国传统文化的鬼力。第三节主要是实践操 作练习。教师带领学生制作端午传传统美食——包粽 子, 感受中医文化在人们生活中的影响 ${ }^{[4]}$ 。

\section{2.4 教学原则}

\subsubsection{1 科学性原则}

中医文化在转化为一门对外汉语选修课时, 因其 内容丰富、涉及范围广, 在设定课程目标、编排教学 内容、选择教学方法等方面都要遵循对外汉语文化教 学的科学理论依据。在课堂讲解中, 教师要遵循课堂 语言规范, 特别是关于中医医理的讲解要科学准确, 操作程序上要规范熟练。

\subsubsection{2 针对性原则}

教师在确定教学对象后, 依据教学对象的特点, 具有针对性的选取教学内容, 制定更符合教学目标的 教学活动设计方案。

\subsubsection{3 趣味性原则}

趣味性在课堂文化教学中是很重要的一项因素。 不同国家之际存在文化差异, 课堂教学的内容和教学 设计要针对教学对象, 采用轻松、活泼的方式为主, 通过多媒体课件的应用以及选取有趣味性的习俗, 比 如制作香囊, 辨别中药材等, 在直观的教学内容中, 激发学生的学习兴趣, 加深学习印象。

\subsubsection{4 课内课外相结合原则}

课内教学时间和场地资源有限, 为满足教学目标 的实现, 增加课外教学, 让学生在亲身实践中了解医 药知识, 学习中医文化。

\section{2 .5 教学方法}

中医文化课最大的难点是通过何种方式能让留 学生最大限度地吸收和接受中医文化, 如何有效地展 示和互动就成了最关键的环节。教师在讲解中医文化 理论时, 可以采用讲授法和多媒体展示直观教学相结 合的方法 ${ }^{[5]}$, 从视觉和听觉两方面进行信息输入; 在 实践操作中, 教师可以将演示法和学生实践操练相结 合, 达到检验教学的目的。为了激发学生的学习兴趣, 在课程中设计小组互动, 鼓励学生实践合作, 提高中 医文化课的学习效果, 加强学生对中医文化的理解和 吸收。

\section{2 .6 教学评估}

教学评估就是把教师和学生在教学过程中的全 部活动, 按照教学的原则, 分析教学活动是否达到设 定的教学目标, 针对学生的习得效果, 评价教师使用 的教学方法以及总体的教学设计是否合理 ${ }^{[6]}$ 。教学评 价分为课前的诊断性评价, 对教学对象的水平有一个 基本评估; 课中的形成性评价, 对教学过程中教师的 输出、学生的输入进行评估, 以便改进教学设计; 课 后的总结性评价, 对学生进行考察, 可以通过考试的 方式, 也可以通过问卷、访谈的方式, 考察教学目标 是否符合学生的语言水平和认知水平; 教学内容是否 突出重难点; 教学效果是否达到教学目标, 学生是否 对中医文化产生进一步了解的兴趣, 有没有提高跨文 化交际水平。

\section{6. 结语}

本文对传统节日端午节中蕴含的中医文化做了 总体的概述, 并以传播中医文化为己任, 针对如何进 行中医文化教学做出了教学的整体设计, 以达到最终 提升留学生对中医文化的接受度和认知度, 扩大中医 在对外汉语教学中的文化影响, 此外, 端午节中的中 医文化内涵与对外汉语文化教学的结合，有利于传播 中医理念, 吸引更多留学生对中医的兴趣。本文在以 传统节日中的中医文化内容进行教学设计的过程中, 还需要不断地加强实践操作, 进行完善和改进, 才能 提升教学水平, 取得良好的教学效果, 从而更好地加 深中医文化在对外汉语教学中的效果和影响力。

\section{REFERENCES}

[1] Wu Zh.G.,(2014)Teaching Chinese as a second 1 anguage-Chinese skill teaching., foreign langua ge teaching and Research Press.,Beijing.

[2] Zhang Y.,(2018)Teaching design of traditional C hinese medicine culture course in teaching Chin ese as a foreign language-Taking the teaching of diet and health preservation in summer as an example. Modern communication, (8). 
[3] Gu Zh.Sh.,(2014) Dragon Boat Festival and anci ent health and epidemic prevention Festival. Co urse teaching, (2).

[4] Chen L.H.,(2019) Dragon Boat Festival custom and health preservation of traditional Chinese medicine [J]. Historical theory (4).
[5] Sun H.Sh.,(2017) A calamus sword can clear a way filth and clear the heart. Health preservati on of traditional Chinese medicine, 5: 26-27.

[6] Liu L.M.,(2021) Research on the application of traditional Chinese medicine culture in teaching Chinese as a foreign language.Educational rese arch. 